\title{
HIGHLIGHTS
}

REPRODUCTIVE ENDOCRINOLOGY

\section{Late-onset hypogonadism: diagnostic categories defined}

Different categories of late-onset hypogonadism can be distinguished by hormone measurements, risk factors and associated symptoms, new data of a cross-sectional survey reveal.

In men, circulating testosterone levels decline from middle age onwards, and an increasing number of older men are being considered for androgen replacement therapy to improve nonspecific symptoms that might be related to testosterone deficiency, such as reduced libido, energy, mood and erectile function, and decreased bone and muscle mass. However, the diagnosis of late-onset hypogonadism and indications for treatment are grey areas.

"Better understanding of the mechanisms underlying 'physiological' aging in the reproductive axis can lead to an improved definition of a true testosterone-deficient state in aging men and rationalize indications for replacement therapy," explains lead researcher Abdelouahid Tajar of the University of Manchester, UK.

With the aim of refining different diagnostic categories of late-onset hypogonadism, Tajar et al. measured levels of testosterone and luteinizing hormone (LH) in fasting blood samples obtained from 3,219 community-dwelling men aged 40-79 years from eight European centers. They then divided the men into four functional categories-eugonadal (76.7\% of participants; testosterone $\geq 10.5 \mathrm{nmol} / \mathrm{l}$ and $\mathrm{LH} \leq 9.4 \mathrm{IU} / \mathrm{l})$, primary hypogonadism ( $2 \%$; testosterone $<10.5 \mathrm{nmol} / \mathrm{l}$ and LH $>9.4 \mathrm{IU} / \mathrm{l})$, secondary hypogonadism (11.8\%; testosterone $<10.5 \mathrm{nmol} / 1$ and $\mathrm{LH} \leq 9.4 \mathrm{IU} / \mathrm{l})$ and compensated hypogonadism (9.5\%; testosterone $\geq 10.5 \mathrm{nmol} / \mathrm{l}$ and LH $>9.4$ IU/l).

The investigator's findings highlight important differences between the categories. Secondary hypogonadism was associated with obesity, and so could potentially be reversible with weight loss, and was independent of age. By contrast, primary hypogonadism, which the researchers points out is probably the genuine form of late-onset hypogonadism, was strongly associated with age, as was compensated hypogonadism. "Sexual symptoms were more prevalent in secondary and primary hypogonadism than eugonadal while physical symptoms were more likely in compensated hypogonadism than eugonadal," adds Tajar. On the basis of their findings, the researchers suggest that compensated

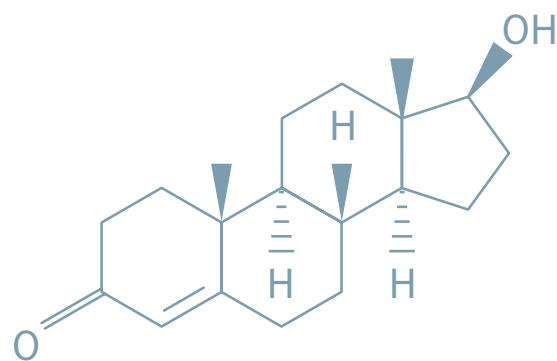

hypogonadism may represent a precursor of overt primary hypogonadism, so recommend continued monitoring of men with this condition to counteract further deterioration.

"Classification of symptomatic elderly men with different testosterone and LH levels into different functional categories of late-onset hypogonadism may provide a more precise pathophysiological framework to refine the diagnosis and ultimately to improve management of this condition," concludes Tajar.

\section{Carol Wilson}

Original article Tajar, A. et al. Characteristics of secondary, primary, and compensated hypogonadism in aging men: evidence from the European Male Ageing Study. J. Clin. Endocrinol. Metab. 95, 1810-1818 (2010) 